\title{
O xadrez do parentesco e o parentesco do xadrez $^{1}$
}

\author{
Roy Wagner
}

University of Virginia

Tradução: Evelyn Martina Schuler Zea e Jose Antonio Kelly Luciani

Universidade Federal de Santa Catarina, Florianópolis, Brasil

\section{Revisão de tradução: Vânia Zikán Cardoso}

Universidade Federal de Santa Catarina, Florianópolis, Brasil 


\section{Resumo}

A comparação real entre o estudo antropológico do parentesco e o jogo de xadrez não é imediatamente aparente a partir de suas propriedades formais, tornando-se relevante apenas quando ambos são vistos como estratégias ou como padrões de eventos acontecendo no tempo. A proporção simples de que ambos compartilham é um tipo de comparação cruzada entre variáveis dualísticas denominadas quiasmas, ilustradas no parentesco pela clássica relação de primos cruzados e no xadrez pela dupla proporção assimétrica entre o Rei e a Rainha, as únicas peças marcadas pelo gênero no tabuleiro, e os movimentos e acenos das outras peças. A diferença pode ser resumida em uma palavra: mating. Xadrez pode ser descrito como o parentesco do parentesco. A falha de compreensão da essência quiasmática ou de dupla proporção de ambos tem resultado em muitos modelos disfuncionais de casamento de primos cruzados e em muitos jogos ligeiros de xadrez.

Palavras-chave: Parentesco. Xadrez. Humor. Práticas de conhecimento. Casamento entre primos cruzados. Atrator estranho. Melanésia.
Abstract

The real comparison between the anthropological study of kinship and the game of chess is not immediately apparent from their formal properties, and only becomes relevant when they are viewed as strategies, or patterns of events occurring in time. The single proportion that both share in common is a kind of cross-comparison between dualistic variables called a chiasmus, illustrated in kinship by the classic cross-cousin relationship, and in chess by the asymmetric double-proportion between the king and queen, the only gendered pieces on the board, and the moves and tokens of the other pieces in the game. The difference may be summed up in the word: mating. Chess may be described as the kinship of kinship. Failure to understand the chiasmatic, or doubleproportional essence of both has resulted in many dysfunctional models of cross-cousin marriage, and many very quick games of chess.

Keywords: Kinship. Chess. Humour. Knowledge practices. Cross-cousin Marriage. Strange Attractor. Melanesia.

ILHA

volume 12 - número 1 
A representação antropológica padrão do "parentesco", apresentada pela primeira vez por Lewis Henry Morgan em 1871, era um padrão estático, útil apenas para fins comparativos, levando a disciplina para uma trajetória de autoinércia ou "estrutural funcionalista", na qual padrão, consistência e, especialmente, relatividade se constituíram como pontos-chaves de referência. Como tal, contrastava fortemente com o modo pelo qual as vidas humanas são efetivamente vividas e pensadas e com a padronização de eventos e a padronização de estratégias. Tanto o campo de jogo quanto o elenco dos jogadores fazem parte de um desenho mais amplo, de um quadro arbitrário para o desdobramento de destinos.

No parentesco cruzamos (mate) no começo do jogo, no xadrez o xeque-mate (mate) acontece no final. A palavra "mate" tem uma etimologia muito diferente em cada caso e um sentido muito diferente, mas é o mesmo som sendo usado basicamente do mesmo modo e muito estratégico.

No xadrez você inicia com todo o seu pessoal ali de uma vez, classificado e ordenado de modo muito específico, e, salvo algumas exceções, você avança, diminuindo seu número no decorrer do jogo. No parentesco você inicia conceitualmente com muito pouco pessoal e avança multiplicando seu número no decorrer do tempo. Em seguida você classifica-os e ordena-os de acordo com categorias muito específicas - geralmente genealogias e linhagens em vez das figuras do cavaleiro, do bispo, da torre e do peão (You can always get more pawns at a pawn-shop ${ }^{2}$.

No xadrez há uma estratégia única conhecida apenas para o jogo em si e cada jogador tenta descobrir em que consiste. Quando um deles se dá conta da estratégia - ela dá conta do outro. No paren- 
tesco há muitas estratégias potenciais, mas todo mundo, incluindo o antropólogo, acha que sabe aquela que conta. Ou ao menos faz de conta, porque não se quer que os outros jogadores vejam suas cartas; em todo caso, a maioria deles está blefando. E aquele que morre com a maior quantidade de estratégias ganha.

O xadrez é um jogo considerado altamente intelectual, mas no final das contas não tem nada de realmente intelectual - é mais como um truque mental de Jedi ou como o papel do malandro (grifter), o tipo de trapaceiro que preda outros trapaceiros como no filme The Sting, de Robert Redford e Paul Newman. O trapaceiro é o meiotermo entre o parentesco e o xadrez, e esse meio-termo chama-se estratégia. Estratégia de quem? Exatamente, você sacou o jogo de uma vez! O parentesco e o xadrez são mundos paralelos, definem contextos sociais, culturais e físicos altamente específicos que mal se sobrepõem. No entanto, há pelo menos um modo no qual eles são uma única e mesma coisa.

E, embora "estratégia" praticamente o explique por completo essa sendo a principal razão pela qual qualquer um se importa com o parentesco, para além de jogos classificatórios estéreis, e também sendo a principal razão pela qual qualquer um se importa com o xadrez, para além de, evidentemente, ganhar -, continuemos. Claro que ninguém se importa em ganhar ou perder no parentesco - de forma alguma! Só alguns indivíduos malconceituados, alguns chamados "homens" e outros "mulheres". Ah, e quase esqueço: "crianças".

Há muitas coisas do parentesco que não valem para o xadrez, e muitas coisas do xadrez que não valem para o parentesco. Mas há uma coisa em ambos que muito nos impele, uma coisa que torna as comparações paradoxais e, portanto, os paradoxos comparativos. Essa é a comparação quiasmática, ou de dupla proporção, aquilo que Tony Crook, que a descobriu em Bolivip, na Papua Nova Guiné, enquanto decifrava o complexo sigiloso da "Casa da Mãe", denomina "mudar o sujeito no meio da frase" - uma espécie de "casamento de primo cruzado" sintático, se me permitem a comparação. Os Daribi, também da Papua Nova Guiné, o chamam de porigi e o descrevem como po begerama pusabo po em sua língua, “a fala que volta sobre si mesma 
na medida em que se fala". Ao perguntar "O que faz de um homem um big man será sua posse de muitas mulheres ou de muitos porcos?", os Daribi responderão: "Um homem que pode falar porigi com efeito obtém todas as mulheres e porcos que ele quiser".

Antes de prosseguir demonstrando o papel crucial que o quiasma exerce tanto no xadrez quanto no parentesco, talvez seja útil entender exatamente que tipo de estratégia está envolvida nele. Por exemplo, o filósofo grego Heráclito ficou conhecido por suas afirmações crípticas, tais como "Imortais Mortais, Mortais Imortais, vivendo uns a morte dos outros, morrendo uns a vida dos outros". Será que isso significa que Heráclito sabia alguns segredos sobre seres humanos e deuses, ou sobre suas estranhas relações, que os outros não sabiam? De modo algum, Heráclito era tão inocente desse tipo de conhecimento quanto você ou eu; ele apenas sabia utilizar bem o ergativo, utilizando-o numa estratégia quiasmática. Uma expressão "ergativa" é aquela na qual uma ação ou verbo convencionalmente ativo é deslocado para um papel passivo, com um aumento exponencial de poder e ênfase. Observe que "viver a morte de outro" é um ergativo exemplar desse tipo, um pouco parecido com "morrer trabalhando" num paraíso do trabalhador; e, quando usado quiasmaticamente numa comparação de dupla proporção, ele invoca um efeito irônico poderoso, como na antiga piada soviética: "Nós fazemos de conta que trabalhamos, e o Estado faz de conta que nos paga".

Em outras palavras, a melhor maneira de guardar - ou mesmo de inventar - um segredo é fazer dele uma função da forma (como o porigi) e não do conteúdo. Desse modo, a estratégia formal compartilhada pelo xadrez e pelo parentesco se parece mais com um golpe (coup) em topologia e matemática do que com as manobras "relacionais" ou emocionais caras aos chamados "humanistas". Deixem-me ilustrar: dito de maneira simétrica e assimétrica ao mesmo tempo (do modo com que Heráclito configurava seus discursos proféticos), o segredo de que não há segredo algum se torna uma meia verdade sobre si mesmo e, portanto, uma dupla verdade sobre qualquer outra coisa-mais ou menos o que os matemáticos da fractalidade chamam de "atrator estranho" (os anciões da Casa da Mãe em Telefolip, 
Papua Nova Guiné, de fato utilizam esse dispositivo como uma estratégia de ensino para seus iniciados; e, em 2000, Mike Wesch e eu pegamos um deles no ato de tentar usá-la - chamada nesse caso "As Duas Bonecas" - com a gente).

No final das contas há, portanto, um problema com esse ilusionismo de dupla incriminação (double-jeapardy illusionism); o que é que o ancião fez com Mike e comigo que ele não teria já feito a si mesmo? Será que o atrator estranho chamado "As Duas Bonecas" não $o$ controlava também? E como é que sua prepotência difere daquela do trapaceiro, do passe de mágica do ilusionista, do grande mestre de xadrez ou, até mesmo, do especialista em parentesco? Era certamente apenas um modo de falar, mas Freud de fato chamou sua psicanálise de "a cura pela fala". E assim também se diz que o jogo de xadrez é muito educativo.

Onde encontramos o quiasma de dupla proporção no jogo de xadrez? O layout do xadrez é um estudo de simetrias contrastivas; há dois lados (ou jogadores), quadros brancos e negros ( 8 x 8) organizados num formato totalmente simétrico, e cada jogador começa com um layout simétrico de peças (bispos, cavalos, torres e peões, tradicionalmente chamados de "homens", mas com gênero não explicitado). Estas são as "quatro forças": sacerdócio, cavalaria, fortificação e infantaria, no regime militar da Antiga Índia, de onde vem o jogo.

E depois há a outra proporção, que é aquela ditada pelas únicas peças no tabuleiro com o gênero explicitado que, de acordo com as regras, devem se encarar frente a frente no tabuleiro - uma assimetria - com o branco quadrado à direita do jogador escolhido por essa cor. Essas peças são a Rainha e o Rei, os elementos mais importantes em jogo, aqueles que têm seus papéis tradicionais da corte revertidos (parte da mesma assimetria). Normalmente, na vida real, é a Rainha quem detém a posição social do reino, enquanto o Rei "manda ver" e é o comandante-chefe. Mas no xadrez esses papéis são invertidos, a Rainha é o guerreiro mais eficaz de todos e o Rei, pela sua posição, detém o valor do jogo. 
Um atrator estranho é o chamado "As Duas Bonecas", pois ele efetivamente energiza (ou seja, ergatiza) o jogo, fazendo dele muito mais que um mero jogo, transformando-o em metáfora do estadismo real. Do ponto de vista da estratégia, isso implica que dois membros da realeza se enfrentem, um contra o outro, em contraponto com as manobras dos dois "exércitos". Basicamente, tudo se refere a cruzamento (mating). Vejamos.

Como duas bonecas Barbie, cada uma tentando ser mais Barbie que a outra. Somos tentados a dizer que temos a mesma contradistinção no parentesco, entre o assim chamado quadro genealógico, que classifica e ordena o esquema, e o jogo de afins, aqueles relacionados ("pela aliança") através da uma explícita interação de gênero. Mas isso é enganoso na medida em que a genealogia é uma função tanto da interação marcada pelo gênero quanto da afinidade, tendo a mesma fonte, e a afinidade é uma função tanto da genealogia quanto do casamento. Portanto, a "teoria da descendência" e a "teoria da aliança" são, como dizem os Norse, ${ }^{3}$ "dois chifres na cabeça da mesma cabra", e não se trata de uma relação de dupla proporção. A chave do quiasma foi dada por Claude Lévi-Strauss nAs estruturas elementares do parentesco.

Nós mesmos bem poderíamos fazer um pequeno exercício de deslocamento de proporções e chamá-lo "O parentesco elementar das estruturas", tão boa foi sua virada ao avançar para uma abordagem positiva ou proativa ao tema. Para completar o átomo do parentesco, segundo Lévi-Strauss, a regra negativa de casamento configurada pela identificação genealógica morganiana deve ser contrabalançada por alguma contraparte explicitamente positiva, uma estratégia de parentesco conhecida por se contrapor à dispersão distributiva das gerações. Assim como há um tabu do incesto, deve haver um tabu do outcest: casar dentro (marrying in), que consolida os ganhos lineares, é tão importante quanto o casar fora (marrying out), independentemente de outras considerações.

Até aqui tudo bem, pois temos uma contraparte de dupla proporção do esquema de classificação e ordem versus aquele de inversão de papéis de gênero encontrado no xadrez, na medida em que a 
relação cara a cara marcada pelo gênero entre homem e mulher é contraposta, no esquema do "átomo do parentesco" lévi-straussiano, pelo esquema do atrator estranho - o parentesco "back to back"4 engendrado pela irmã do esposo e o irmão da esposa e sua respectiva prole -, os assim chamados "primos cruzados" no repertório de praxe do parentesco.

A ressalva explícita do argumento dos "primos cruzados" de Lévi-Strauss, que "a mulher poderia muito bem ter sido o pai de alguém, assim como o pai poderia ter sido a mãe de alguém", foi feita, em diferentes momentos e contextos, por Radcliffe-Brown e por meus anfitriões Barok da Nova Irlanda (Papua Nova Guiné), cada um sem saber da existência do outro. Ela sugere um contrajogo imagético (imaginal counterplay) de reprodução puramente metafórica acontecendo por trás das cenas do tratado de parentesco morganiano - como as intrigas metafóricas do Rei e da Rainha no xadrez vis-à-vis as manobras claras e diretas de seus "exércitos".

Assim, o casamento dos primos cruzados, por mais classificatório que seja, é uma resposta fácil, uma solução apressada, para o dilema colocado pelo argumento de Lévi-Strauss, algo assim como um comprometimento exagerado com a premissa. Uma relação de parentesco motivada por um atrator estranho não tem um resultado estrutural mais certo ou previsível que uma jogada no xadrez. Ambos são estocásticos, determinados tanto pela sua própria presença quanto por outros fatores em jogo. Os Daribi, que chamam seus primos de 'hai', dizem que são "exatamente iguais aos irmãos", mas com uma diferença importante. Já que pertencem a diferentes grupos de partilha de bens, os 'hai' masculinos devem trocar pagamentos contínuos de bens para resgatar as demandas de direito de casamento levirático que ambos compartilham em relação à herança das esposas uns dos outros.

Só encontrei um caso de casamento de primos cruzados de verdade em Karimui; isso foi em Hagani, um lugar onde morei. Um homem de 'Sora' exigiu seus direitos sobre uma mulher Hagani solteira. Durante dias ele ficava vadiando nos arredores da maloca gritando: "Ela é minha prima cruzada, porque não posso casar com ela?". 
Finalmente a gente se cansou tanto disto que simplesmente o deixamos tê-la (como esposa).

Mas vocês não deveriam bater em ambos e dar-lhes uma dura lição sobre como eles são pessoas ruins?

Bom, claro, idealmente sim; mas naquele momento nossas relações com 'Sora' se tornaram tão incertas que decidimos desistir.

Entre os Usen Barok "matrilaterais" de Nova Irlanda a situação é mais complexa; eles chamam esse tipo de casamento de "casamento com o tau (verdadeira irmã do verdadeiro pai) ou gogup (primo cruzado)". Os moradores das duas aldeias ao norte, falantes de um dos subdialetos, colocaram a questão do seguinte modo: "Os ancestrais jamais teriam tolerado outra coisa que a adesão rigorosa à regra de casamento com o tau ou gogup; no entanto, com a erosão dos valores morais nestes tempos modernos, tudo é menos rígido, particularmente nas aldeias ao sul".

Entre as três aldeias ao sul, falantes de outro subdialeto e onde eu morei, eles contestaram:

Os ancestrais jamais teriam tolerado algo tão incestuoso quanto o casamento como tau ou gogup; no entanto, agora que os preceitos morais estão menos rígidos, o pessoal de Belik e Lulubo está livre para seguir seus desejos. Isso é particularmente verdadeiro no caso da aldeia Lulubo chamada 'Giligin', onde todos casam com seus tau ou gogup.

Como eu tinha bons amigos na "Ilha de Giligin", 5 como eu a chamava, decidi checar as coisas. Felizmente, um deles não era apenas fluente em inglês, mas também alfabetizado; com sua ajuda coletei uma genealogia completa de Giligin com cinco gerações de profundidade e examinei cada um dos casamentos com cuidado. Mesmo levando em consideração o assim chamado parentesco "classificatório" ou cálculo de parentesco por categorias, não consegui encontrar nenhum caso de casamento com o tau ou gogup em todo o conjunto. Quando terminei, disse para meu colega: "Agora posso ver que cada um dos casamentos em Giligin se deu com um tau ou gogup". "Sim", ele respondeu, sorrindo; "como eu te disse, nós aqui em Giligin somos gente estritamente moral". 
Falando em atratores estranhos, o único caso de casamento com um primo cruzado direto que eu encontrei em toda a área Usen foi na própria aldeia onde eu morei, Bakan, precisamente na área que negava categoricamente tal prática. Tratava-se de um de meus melhores amigos que morava ao lado de minha casa. Quando lhe pedi para explicar o caso, ele disse: "foi uma questão de pura casualidade, eu não tive nada a ver com isso". Em seguida, esticando-se ao máximo, e ele tinha uma altura considerável, ele explicou: "Sou conhecido como um dos homens mais morais desta área toda".

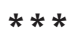

O xadrez é um jogo no qual há uma única díade, aquela dos dois jogadores que se revezam para fazer suas jogadas, assumindo o papel de uma das seis peças com funções específicas, como as atribuições profissionais de um sistema de castas militar. O parentesco não é um jogo, é a vida para aqueles envolvidos nele e um trabalho sério para aqueles que o estudam. Outra grande diferença é que no parentesco, ainda que idealmente organizado em díades, cada participante está envolvido em muitas relações diferentes ao mesmo tempo. E ainda que o envolvimento seja simultâneo, a partir do momento do nascimento e mesmo antes, cada participante parente deve aprender a diferenciar o que termina sendo um modo único, difuso e englobante de relacionamento, e adaptar sua ação às especificidades de cada papel na relação (relationship role) determinado pela cultura.

Não há nenhuma analogia direta disso no xadrez que é, em contraste, digital no modo de jogar. Tanto Radcliffe-Brown quanto Bateson mostraram que a adaptação do relacionar-se no parentesco está limitada a três modos genéricos de imitação analógica, cada qual sendo uma variação sobre um mesmo tema, o de relacionar-se adequadamente. Esses são 1) relações de respeito (de deferência), como aquelas de adoração, nas quais as obrigações entre o mais novo e o mais velho são visivelmente exageradas; 2) relações de evitação, nas quais a referida evitação ou ausência de relação entre as partes constitui a substância da relação, ela mesma; e 3 ) relações jocosas, nas 
quais a performance de comportamentos ou de falas inapropriadas, ou ambas, oferecem ao outro a opção de aceitação ou de rejeição, e assim da afirmação ou da negação da vinculação preferida. Essas três modalidades dividem o jogo dos papéis de parentesco entre elas, e a necessidade de diferenciar entre elas é uma das primeiras coisas que uma criança aprende.

A contraposição entre a suposta falta de seriedade, nas relações jocosas, e o fingido exagero de seriedade, nas relações de respeito ou deferência, nos leva à questão polêmica do propósito ou do projeto geral do parentesco. Respondê-la não é um objetivo fácil (questionála é ainda pior), pois não é nem estrutural nem funcional, e não surpreende descobrir que ela depende do mesmo paradoxo de dupla proporção - o atrator estranho -, que inferniza seu entrelaçamento nos assuntos cotidianos. O parentesco é feito de "conexões estabelecidas entre os vivos em nome dos mortos" e, ao mesmo tempo, "conexões entre os mortos em nome dos vivos" (Wagner, 2001), e, portanto, nem "vida" nem "morte" podem nos oferecer uma resposta que não seja desdenhosa. "Num enigma cuja resposta é 'xadrez,'" escreveu Jorge Luis Borges (1998), "qual é a palavra que nunca é mencionada?".

Em outras palavras, em vez de soluções, poderíamos começar a adivinhar no que consiste o enigma, ele mesmo. O enigma também não é fácil, embora nos faça lembrar as últimas linhas de um soneto escrito por Edna Saint Vincent Millay (1934) sobre os antigos egípcios:

Their will was law, their will was not to die.

And so they had their way; or nearly so. ${ }^{6}$

Ainda assim, obtemos algumas pistas na obra de Richard Huntington entre os Bara de Madagascar e na obra de Gregory Bateson entre os Iatmul do Rio Sepik em Papua Nova Guiné. A morte, para os Bara, consiste na cristalização dos relacionamentos e do status adquiridos na vida - o próprio fato ou a matéria da morte ameaça os vivos com uma espécie de perigo de congelamento profundo, uma absorção contagiosa da espontaneidade da vida numa matriz perene de perfeição cristalina. ("O perfeito", como diz o ditado, "é o 
inimigo do bom."). Diante da presença da morte, os Bara convencionalmente fazem todo o possível para reafirmar a centelha da vida; eles estouram uma boiada na aldeia, criam confusão, ficam doidamente bêbados com rum, e os adolescentes em idade de casar se reúnem na mata, cantam canções obscenas e transam promiscuamente. Se Millary tivesse escrito um soneto sobre as práticas Bara, ela poderia tê-las chamado "morte acalentada" ("death warmed over").

No entanto, o que os Bara têm a nos dizer sobre as relações de parentesco tem pouco a ver com humor, seriedade ou evitação desprezível; ante a desolação da mortalidade e com o que aprendemos a chamar de "culpa do sobrevivente", eles fazem de conta - fazem de conta com (verdadeira) violência, hilaridade, embalo alcoólico e êxtase sublime do ("Ah, se minha mãe me visse agora") coito ilegítimo ("adultério de Borgonha", como um amigo meu costumava chamálo - um bom nome para uma nave espacial).

E essa é uma das chaves - o "poderia ter sido" ou a "filosofia do como se" - do enigma com o qual supomos estar lidando; não há relação de parentesco na terra que não seja em certo ponto uma questão de fazer de conta (ainda que no xadrez tudo isso seja fatalmente sério), uma arte sútil que toda criança aprende desde muito cedo. Não há tal coisa como parentesco não fictício; quando o faz de conta desmorona, também desmorona o parentesco, e temos algo como uma lei de ferro do parentesco: o parentesco real não é o que está acontecendo em nenhum pretexto que de outro modo possa ser confundido com relações de parentesco.

Nem a morte mesma é o que se achava que seria, eis a lição no Naven de Gregory Bateson. Mesmo sendo um contraefeito da dualidade integral da vida Iatmul, algo que Bateson destacou e denominou cismogênese, o rito fúnebre honorífico dos Iatmul é um bom exemplo de obviação. Essa é uma alternativa altamente contraintuitiva em relação ao sentido usual de completude ou consumação de uma vida humana, uma negação positiva na qual o resultado final não é nem o sujeito ("vida") nem sua antítese ("morte"). O ser humano obviado ("Tod und verklärung", "Morte e transfiguração", como o chamou Richard Strauss) não está nem vivo nem morto. 
Na descrição de Bateson, todos os apetrechos simbólicos da vida do falecido e suas realizações são reunidos sob a forma de uma figura humana substituta, uma efígie que representa o falecido.

Esse boneco foi montado por membros da metade iniciatória do morto. Era uma demonstração exagerada da grandeza de sua metade, e quando o boneco ficou pronto, todos os homens, de ambas as metades, reuniram-se em torno dele. Os membros da metade oposta apareceram um por um para reivindicar feitos equivalentes. Um homem disse: "Tenho uma ferida aqui no quadril, onde os (homens de) Kararau me atingiram. Tomo para mim esta lança", e pegou a lança que estava apoiada no quadril do boneco. Outro disse: "Matei Fulano. Tomo para mim esta lança", e assim por diante, até que todos os emblemas de bravura foram removidos (Bateson, 2006, p. 202).

As práticas do ritual fúnebre Iatmul não apenas respondem ao enigma da vida na morte e da morte na vida; elas o obviam. Obviação é o destino dos símbolos, sendo para eles tão natural como a morte para os humanos. A palavra "obviar" significa não apenas "tornar óbvio aquilo que antes era obscuro", mas também, segundo sua definição no dicionário (em inglês, para obviation), "prever e descartar." Prever a morte na vida é descartar a vida na morte. No que diz respeito ao papel de Bateson em relação a isso, como antropólogo, bem poderíamos concluir que "o historiador narra a história, a literatura interpreta a história, mas o antropólogo obvia a história", tornando-a inócua como se, em primeira instância, jamais tivesse sido. O parentesco não é obviado na forma como nós o entendemos, mas na forma como ele nos entende. Ainda que "underdetermine" talvez seja uma palavra melhor que "understand", como no soneto de Millay.

Isso traz uma virada nova para a nossa questão, pois não temos nada em todo o nosso repertório epistemológico que sugira que algo tão inerte e abstrato como "o parentesco" possa ter algum poder de compreensão, nem que alguém possa, como o fez Ingmar Bergam no filme $O$ sétimo selo, "jogar xadrez com a morte" (shakspielen med döden), ainda que seja exatamente isso o que os Iatmul fazem no seu ritual fúnebre. Os Iatmul são "compreendidos" ("understood") tão bem 
nesse ritual que não sobra nada pelo qual possa valer a pena viver ou morrer. De modo mais geral, no que diz respeito ao parentesco, nossos padrões de pensamento não estão apenas incorporados (embodied) nas coisas nas quais pensamos (eventos, circunstâncias, objetos), mas elas também correm o perigo de serem "entendidas" bem demais ou não suficiente bem por nossos pais - que é o mais próximo que podemos chegar ao parentesco encarnado (kinship incarnate) - e, portanto, se desenvolverem de modo absurdo. (Os descendentes de um verdadeiro antropólogo sempre correm algum perigo de se desenvolverem de modo absurdo - mas, então, considerem a fonte.)

Além disso, é precisamente essa inversão de sujeito e objeto, o ergativo, o atrator estranho, que vimos trazer tanto o xadrez quanto o parentesco do entalhe ("out of the woodwork") para o mundo da realidade vivida, especialmente quando consideramos não apenas o que os constitui, mas o que os fortalece (empower).

Metáforas falam para você; elas têm agência e mentes próprias (mesmo admitindo que sejam um tanto esquizofrênicas). O xadrez faz suas mãos se moverem com uma paciência e destreza que nem um amante toleraria. No que diz respeito às peças de xadrez, elas mesmas: "Não é a mão de Deus que nos move, mas o deus da mão". O parentesco que nos "compreende" ("understands") melhor do que nós podemos compreendê-lo e o xadrez que faz com que o jogador entre em estados "não naturais" de concentração intensa são parte de uma retroalimentação ("feedback loop") englobante de dupla proporção que se estende para muito além dos limites da "sociologia da mata" e dos torneios de grandes mestres. Trata-se de um processo que também envolve as propriedades significativas da linguagem tanto os modos pelos quais a língua se relaciona consigo mesma quanto os modos pelos quais os falantes da língua se relacionam uns com os outros -, e esse entrelaçamento faz parte de nossa herança tanto quanto a infraestrutura de dupla hélice faz parte do DNA.

Sempre houve uma suposição tácita entre os que estudam o parentesco de que seu tema está de algum modo relacionado à necessidade de solidariedade humana - famílias, vínculos, grupos e esse tipo de coisas. E embora seja uma ideia reconhecidamente 
"funcionalista", relacionada de algum modo com a noção reconhecidamente "estruturalista" de que a metáfora ou o tropo é a fonte e o fornecedor exclusivo de significado numa língua, as conexões necessárias para aproximar ambas se estendem para além dos limites de disciplinas e requerem um "pensar fora dos padrões convencionais" ("thinking outside of the box").

Assim, bem poderíamos começar do zero. Nunca encontramos um coletivo humano que não possuísse tanto uma língua falada quanto um modo de se relacionar expresso através de uma terminologia de parentesco. Portanto, podemos concluir que ambos são, de certo modo, necessários para a existência e a composição da espécie Homo sapiens, a espécie que, diga-se de passagem, foi responsável pelo conceito de espécie em primeiro lugar. (Nós somos os grandes classificadores do mundo e nos classificamos como tais.)

Mas o sentido é o "coringa" ("wild card"), por assim dizer, uma "caixa" ("box") que deve necessariamente pensar fora de si mesma reclassificar-se para além da habilidade de classificar o que está fazendo no processo de fazê-lo. Ninguém pode dizer exatamente o que uma metáfora nova ou inovadora - uma reinvenção da língua como o foi - significa, até que, ou a menos que, ela já esteja "cansada" e tenha se classificado, ela mesma, entre os significantes familiares e convencionais que compõem as propriedades lexicais da linguagem.

Trata-se de um modo muito enfadonho de colocar o assunto, e já foi dito muitas vezes antes. Mas o que há de dizer sobre isso é que o tropo ou a metáfora sempre surge ao fazer conexões cruzadas improváveis e não convencionais no léxico, criando uma identidade entre duas partes distintas da língua, assim como uma nova estratégia no xadrez avança ao se fazerem combinações improváveis entre peças e jogadas (um knight-fork, por exemplo, uma de minhas favoritas junto com, é claro, o adultério de Borgonha). Para dizê-lo sucintamente, a metáfora é a estratégia de cruzamento (mating) e significação da linguagem, a forma necessária na qual a linguagem se relaciona consigo mesma. Do mesmo modo, a terminologia de parentesco, o código de referência necessário das relações de parentesco ( sem o qual ele não se reconheceria pelo que pretende ser) é a maneira pela qual os falan- 
tes de uma língua se relacionam entre si. Ambos são parte integrante da reprodução da linguagem através de seus falantes, e a reprodução de falantes, eles mesmos, por meio da linguagem.

Um dos melhores e mais famosos adágios de Gregory Bateson era "Você não pode não relacionar-se". Isso é inegavelmente certo, mas infelizmente leva à falácia de assumir a realidade de "relações" ingênuas e espontâneas, uma espécie de dano colateral deixado pela era "psiquiátrica" dos anos 1970, quando se podia de fato obter dinheiro do governo para fingir esse tipo de coisa. Até para os jogadores de xadrez a necessidade de relações face a face tem sido subvertida pela Internet. Relacionar-se, que significa "colocar os lados juntos", é básico e essencial, e define a condição humana tanto dentro quanto fora do tabuleiro de xadrez. Há uma grande diferença aqui. Devemos psicoanalisar o cavaleiro para descobrir "como se sente" ao mover dois quadros para cima e um para o lado? Acho que não.

O xadrez coloca o termo da moda "relação" em destaque. Vistos do alto, os movimentos possíveis do cavaleiro descrevem um octógono, mas infelizmente um cavaleiro real só pode acessar uma dessas posições por vez. Os movimentos do bispo descrevem uma matriz angular - a torre -, um sistema de coordenadas cartesiano, mas apenas o tabuleiro mesmo descreve todos esses de uma só vez. Não se trata necessariamente do quebra-cabeça do tipo cubo de Rubix bidimensional de quatro quadros (de fato $8 \times 8$ ) que aparenta ser, pois é igualmente concebível num formato diagonal e também pode ser visualizado como uma série de octógonos de cavaleiro entre-encaixados. Cada jogador, ou "lado", encara uma perspectiva especular de seu layout estratégico, "consulta" o espelho de xadrez relacional, com a singular exceção das duas peças com gênero explicitado, a Rainha e o Rei.

Em todo caso não há respostas fáceis para a questão por que os seres humanos consultam espelhos; talvez seja a forma de contrainteligência própria da natureza. Pois aquele que você vê no espelho tem os lados invertidos, assim como a dianteira e a traseira, e ninguém jamais te verá dessa maneira. É claro que isso oferece vantagens ao cruzamento (mating), em ambos os sentidos do termo; 
e, levando tudo em consideração, é a visão do xadrez de você mesmo: "faça a jogada e cruzamento (mate) em dois (movimentos)". (Me olho rapidamente no espelho antes de sair, e assim o faz minha namorada; e, mesmo que o encontro em si não dê em nada, eles dois se divertem juntos - quase como se estivessem jogando um jogo.) Mas quem são esses misteriosos eles que acabam de nos roubar nossa noite? Prossigamos.

A verdadeira diferença entre um "lado" e outro, ou entre jogo e realidade, aparece com o realinhamento de gênero no que diz respeito à lateralidade. Normalmente no jogo da vida um indivíduo tem apenas um gênero e dois lados, a direita e a esquerda. No xadrez, no entanto, cada jogador joga num lado só, mas tem dois gêneros, um Rei e uma Rainha, um à esquerda e outro à direita. No contexto do jogo, em contraposição à vida real, os jogadores não são verdadeiramente seres humanos, mas estão jogando os papéis do que tenho chamado de antigêmeos (Wagner 2001, Capítulo 4), uma subvariante de propósitos cruzados (cross-purposed) da forma humana que de alguma maneira é necessária para a nossa existência. Eles fazem tudo aquilo que nós não podemos, e nós fazemos tudo aquilo que eles não podem ("Eles lançam nossos dados, nós lançamos os deles") (Wagner, 2011), ou nas palavras da canção tema de Mary Tyler Moore: "they can take a nothing date and make it seem worthwhile".

Normalmente não há tal coisa como prova no xadrez; há regras, jogadas e bastante execução. (Imaginem Robespierre tentando substituir uma peça chamada "A Guilhotina" pelo Rei e pela Rainha.) Mas a prova dos antigêmeos no xadrez é de que o Rei e a Rainha trocaram seus papéis normativos - a Rainha assume o papel normalmente atribuído ao Rei na vida real: fazendo jogadas legais e elaborando a estratégia; e o Rei exerce o direito de posição e status social, pois ele, pela sua posição, possui o valor do jogo em si.

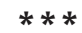

O jogo de xadrez, é claro, não tem nada a ver com cruzamentos (matings) humanos, jogos de poder ou arranjos domésticos, pois, 
mesmo em seu próprio mundo de fantasia, ele pertence ao topo da cadeia alimentar política. Repleto de fantasias de casas reais e seus jogos de poder, é todo sobre poder e o que deve ser feito para manter o poder enquanto se controlam os movimentos dos outros. O parentesco, é claro, não tem nada ver com isso... ou tem? No momento em que se torna um objeto de estudo antropológico já é quase uma abstração matemática, um gerador de eventos que o seu parente comum dificilmente reconheceria ("Quem, eu? Um primo cruzado? Jamais na vida. Eu sou um primo de beijinhos, é só perguntar para a minha mãe, tia gêmea"). Ainda assim, como ocorre nas crises domésticas mais corriqueiras, trata-se de uma negociação na margem de lucro de controle e credibilidade. Pensando nisso, nossa reação usual a um gerador de eventos não tem nada a ver com o que ele é ou como ele funciona. Dogen, um sábio japonês do século XII, escreveu: "What is happening here and now is obstructed by happening itself; it has sprung free from the brains of happening".

Numa manhã de 1989 eu estive ocupado com o que pensei configurar uma grande descoberta na época: que o incesto não é um objeto tabu ou uma forma de mau comportamento, como havíamos pensado, o oposto do parentesco, mas antes seu perfeito apositivo. É o conteúdo sem forma de todas as relações de parentesco em contraposição à forma sem conteúdo do modo como têm sido descritas e estudadas. Transportado, comecei a esboçar o primeiro retrato de grupo dos antigêmeos, que chamei "the twincest" ("o gemeocesto"), "the icon of incest" ("o ícone do incesto") e "the mirrorgender symmetries" ("as simetrias do espelho-gênero").

Mas o tempo realmente voa quando você está se divertindo, e percebi que tinha me esquecido de revisar meu correio naquela manhã. Quando o fiz, encontrei um copião do manuscrito "The Incest Passions", de Jadran Mimica (Mimica, 1991), o melhor estudo e de longe o mais articulado que foi concebido até agora sobre o tema do incesto como uma fenomenalidade sui generis. Mas essa descoberta, como Mimica bem sabia, não vem ao caso quando falamos que a prática de fato, regular e mesmo compulsiva de relações manifestamente incestuosas em todas as sociedades modernas, no âmbito das 
relações familiares mais próximas, excede todas as expectativas razoáveis. Para entender o que isso significa e por que continua, especialmente entre pessoas altamente qualificadas em sociedades industriais modernas, teríamos que ter não apenas um tabu do incesto (incest taboo) mas também um "outcest taboo". E se esse "outcest taboo" funciona tão mal quanto parece ser o caso do tabu do incesto, então todas as racionalizações ou irracionalizações feitas para sustentá-lo também não valeriam nada, pois não é de pensar que se trata o comportamento familiar. Trata-se de controle.

O parentesco, como a história, o processo natural e a estratégia da máquina, pressupõe a lógica da consequencialidade, ou causa e efeito, no acontecer das coisas. No entanto, a relação é um indício de algo completamente diferente, parecendo mais com a antilógica da ironia, na qual nos é dado primeiramente o efeito, como no cenário de abertura ou "armação" de uma piada, e depois somos surpreendidos com a improvável causalidade do desfecho (punch line). Mas, mesmo colocado desse modo, não deixa de ser algo singular, uma piada sobre si, pois piadas e relações - basicamente chaves inglesas jogadas na maquinaria do pensamento - não se enquadram na consistência de pensar as coisas de trás para frente (como se tivéssemos descoberto o sistema perfeito para o pensamento não sistemático), mas carregam uma desqualificação inerente na estratégia de seu dizer ou resolução (working out). Elas celebram "the uncanny" (o estranho).É improvável, a partir desse ponto de vista, que as relações, assim como o incesto e o "outcest" dos quais dependem, tenham tido alguma vez um início - seria como procurar a origem de uma piada (Wagner, 2001). As relações só foram palco das atenções mais tarde na forma de "parentesco", quando as racionalizações de causa e efeito foram desenvolvidas para convertê-las em linhas de descendência, genealogias, relações de afinidade e assim por diante, pois para que servem os parentes sem nada para aparentar (for what good are relatives with nothing to relate)? Não é apenas difícil, mas quase impossível para um antropólogo imaginar como era o acasalamento entre os assim chamados povos pré-culturais sem pensar imediatamente no "casamento", nem que seja apenas para projetar um padrão que possa ser 
negado convenientemente por um antitermo tal como não casamento. É inevitável que isso leve o pré-historiador, outrora um indivíduo são e sensato, a projetar uma dessas estratégias clássicas do "homem natural":

Antes dos seres humanos, como os conhecemos, evoluírem, eles se acasalavam através de um sistema primitivo que poderia ser chamado de "não-casamento", tinham uma prole inconcebivel através de uma forma do que hoje conhecemos como disseminação, que deixava todos se sentindo vazios e sem raízes. Apenas agora, retrospectivamente, é que podemos traçar seus movimentos na lama, usando lascas e ferramentas de pedra que mal arranham a superfície.

O xadrez, é claro, é puramente "simbólico" (diga isso a um grande mestre e, em seguida, saia da frente), mas o modelo de parentesco que tenho revisado aqui é algo mais que isso. Ele não tem necessariamente uma origem nem um término, nem que seja pelo fato de que seus significados e suas relações, como tenho mostrado, são tecidos mútua e retroativamente a partir da mesma matriz geradora que tenho chamado de atrator estranho ou quiasma de dupla proporção. Isso teria que incluir tanto o tabu do incesto quanto sua variante do outcest, a arbitrária "regra, porque tem de haver regras" sobre a qual LéviStrauss afirmou todo o argumento do incesto-cum-reciprocidade $\mathrm{n} A s$ estruturas elementares do parentesco. Mas vimos que as interdições e as reciprocidades desse tipo produzem tanto a proibição quanto a coisa proibida (ou seja, tanto a prática do incesto quanto sua proibição) a partir do mesmo fio condutor e com o mesmo jeito generoso com o qual os Daribi tanto afirmam quanto negam a "irmandade" dos primos cruzados, e os Barok inadvertidamente tanto praticam como proíbem o casamento direto de primos cruzados, o que resulta em ardor moral respeitável e autocontradição em cada caso. Claro, quando lidamos com um atrator estranho, a tradicional exceção que prova a regra se converte rapidamente na regra que prova a exceção, então é claro que tem que existir algum povo ("em algum lugar") que segue a regra de casamento entre primos cruzados diretos precisamente como Lévi-Strauss o tinha prognosticado. Em 1964 eu passei alguns dias com um povo assim, os falantes de Yagaria da aldeia Lagaiu, ao

\section{ILHA}


leste das terras altas da Papua Nova Guiné. Muito cuidadosamente, consultando um grupo de anciões, consegui elicitar sua terminologia de parentesco, correlacionando-a exaustivamente com o registro genealógico e determinando que eles se casavam seguindo um regime estrito de casamento de primos cruzados bilaterais (eles denominavam a categoria de linhas casáveis de devo'a). Ainda que não tenha permanecido no lugar tempo suficiente para ver como o "sistema" funcionava na prática, aposto que funcionava, pois os considero de raciocínio muito agudo.

Onde mais na ciência podemos encontrar irrelevâncias tão picarescas? Nosso herói Gregory Bateson desenvolveu a teoria do "double-bind" da esquizofrenia a partir do modelo da cismogênese de dupla proporção que ele descobriu no seu trabalho entre os Iatmul. Embora tenha permanecido em voga entre os psiquiatras por um tempo bem reduzido e logo perdido território para outras terapias mais "clinicamente corretas", sua teoria imitava os sintomas da esquizofrenia como nenhuma outra coisa no mundo (ninguém jamais conseguiu curar a esquizofrenia nem o casamento de primos cruzados). Muitas vezes, o melhor que podemos fazer é imitar. Há rumores, por exemplo, de que nosso sistema solar (o sol e seus corpos satélites) se desenvolveu pelo acréscimo gravitacional a partir de uma nuvem nebulosa em forma de um disco primordial. Nesse caso a gravidade seria o primum mobile e a maior parte da gravidade no sistema solar é investida no próprio sol. Mas é preciso parar um momento, pois há uma outra proporção nessa cismogênese, já que a maior parte do momento angular (que é a contraposição necessária da gravidade) no sistema solar investe nos planetas, satélites, asteroides, e até mesmo na tênue nuvem de Oort. Daí que outra "origem" para o todo é uma possibilidade real, que é aquela segundo a qual o sol teve uma vez uma estrela companheira localizada na vizinhança orbital de Júpiter, uma estrela cuja explosão redistribuiu o momento angular do sistema sob o padrão que hoje encontramos. Já que nenhuma hipótese exclui a outra, a questão de qual é a "correta" é tão trivial e inconclusiva quanto a questão de quão precisa a relação de primos cruzados deveria ser formulada, ambas as questões requerendo um atrator estranho. O problema em pensar as coisas desse 
modo, e do atrator estranho, se posso ser tão ousado, é o problema de autoabsorção e autoenvolvimento agudo; é simplesmente que um sistema formulado desse modo não tem a habilidade de sair de si mesmo e de se ver como aquilo que é.

\section{Notas}

1 Nota do Editor (NE): Esta conferência, apresentada no Seminário Antropologia de Raposa, está sendo publicada simultaneamente no Hau: Journal of Ethnographic Theory, v. 1, n. 1, 2011.

2 Nota do Revisor (NR): Pawns são peões, mas pawnshop é uma loja de penhora na qual é possível encontrar objetos os mais variados, não resgatados de sua penhora e postos à venda por preços baixos.

3 Nota do Tradutor (NT): Noruegueses e escandinavos.

4 NR: Back to back significa contínuo ou consecutivo, mas o jogo de palavras aqui também se refere ao significado literal de coisas posicionadas de costas uma para a outra.

5 NR: Há aqui uma brincadeira com Gilligan's Island, um popular programa da televisão americana dos anos 1960.

6 "Sua vontade era lei, sua vontade era não morrer / E assim eles tiveram seu caminho; ou quase."

\section{Referências}

BATESON, Gregory. Naven: um esboço dos problemas sugeridos por um retrato compósito, realizado a partir de três perspectivas, da cultura de uma tribo da Nova Guiné. Tradução de Magda Lopes. 2. ed. São Paulo: Ed. USP, 2006.

. Naven: A Survey of the Problems Suggested by a Composite Picture of the Culture of a New Guinea Tribe Drawn from Three Points of View. Second revised edition. Berkley: University of Stanford Press, 1958.

BERGMAN, Ingmar. The Seventh Seal. Stockholm: AB Svensk Filmindustri, 1957.

BORGES, Jorge Luis. The Garden of Forking Paths. New York: Penguin Books, 1998. (Collected Fictions, 119-128).

CROOK, Tony. 1997. Growing Knowledge: Exploring Knowledge Practices in Bolivip, Papua New Guinea. PhD Thesis - University of Cambridge, 1997.

DÔGEN, Zenji; NISHIJIMA, Gudo Wafu; CROSS, Chodo (Trans.). Master Dogen's Shobogenzo. Berkley: Numata Center for Buddhist Translation and Research, 2008. v. IV.

\section{ILHA}


GLEICK, James. Chaos: The Making of a New Science. New York: Viking, 1987.

JORGENSEN, Dan. 1981. Taro and Arrows: Order, Entropy and Religion Among the Telefolmin. PhD Dissertation - University of British Columbia, 1981.

LÉVI-STRAUSS, Claude. The Elementary Structures of Kinship. London: Eyre and Spottiswode, 1969.

MIMICA, Jadran. The Incest Passions: An Outline of the Logic of Iqwaye Social Organization. Part 1. Oceania, v. 62, n. 1, p. 34-58, 1991a.

. The Incest Passions: An Outline of the Logic of the Iqwaye Social Organization. Part 2. Oceania, v. 62, n. 2, p. 81-113, 1991b.

MORGAN, Lewis Henry. Systems of Consanguinty and Affinity of the Human Family. Lincoln: University of Nebraska Press, 1997.

RADCLIFFE-BROWN, Alfred. On Joking Relationships. Africa: Journal of the International African Institute, v. 13, n. 3, p. 195-210, 1940.

SAINT VINCENT MILLAY, Edna. Epitaph for the Race of Man: In Wine from these Grapes. New York: Harper \& Brothers, 1934.

WAGNER, Roy. An Anthropology of the Subject. Berkley: University of California Press, 2001.

WARD, David S. The Sting. New York: Universal Pictures, 1973.

Recebido em: 29/09/2011

Aceite em: 10/10/2011 